\title{
Cefetamet Pivoxil Hydrochloride
}

National Cancer Institute

\section{Source}

National Cancer Institute. Cefetamet Pivoxil Hydrochloride. NCI Thesaurus. Code C98222.

The hydrochloride salt form of cefetamet pivoxil, a pivalate ester prodrug form of a cefetamet. After oral administration of cefetamet pivoxil hydrochloride, the ester bond is cleaved, releasing active cefetamet. 